\title{
A CASE OF FIBROMA OF THE LEFT VENTRICLE IN A CHILD OF 4 YEARS
}

\author{
BY \\ URSULA JAMES and MARGARET H. STANFIELD \\ From the Elizabeth Garrett Anderson Hospital, London
}

(RECEIVED FOR PUBLICATION JUNE 30, 1954)

In view of the rarity of primary benign tumours of the heart, particularly of fibromata, the following case of mural fibroma of the left ventricle and interventricular septum seems worth recording.

\section{Case Report}

L.M., aged 4, was admitted to hospital with a diagnosis of paroxysmal tachycardia. She had been perfectly well until two days before admission when she developed a cold, became listless and refused food. On the day of admission she started to vomit and the general practitioner was called in. He found a heart rate of about 200 beats per minute and sent her into hospital.

Her early history was entirely normal; she was the first child of healthy parents, and a brother of 6 months is quite well. She had been seen by doctors at the infant welfare clinic, and at home during an attack of measles, and no suggestion of cardiac abnormality had ever been made.

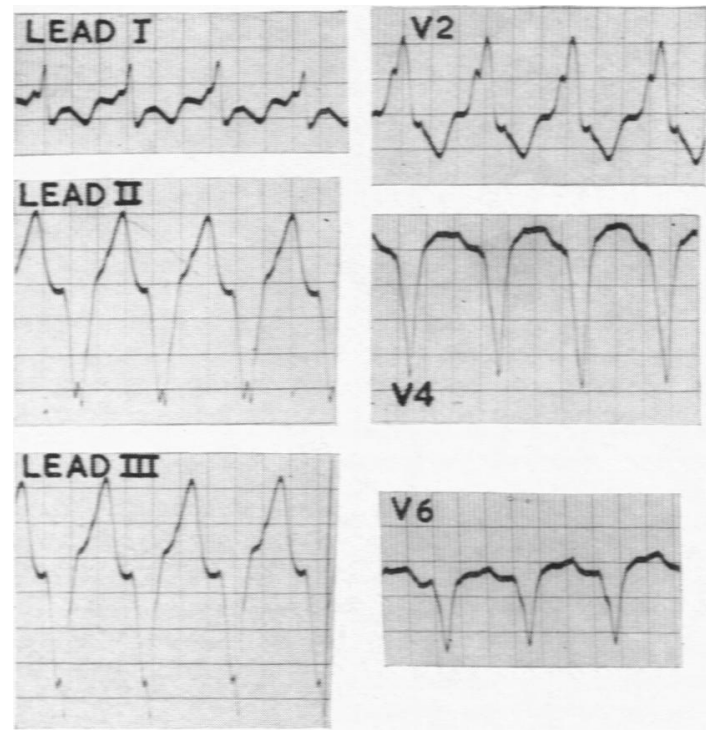

FrG. 1.-E.C.G. taken on admission showing paroxysmal ventricular tachycardia.
On admission she was very quiet and sweating profusely, but was not distressed. Her pulse was uncountable and the apex rate about 180 per minute. The apex beat was diffuse and the left border of the heart

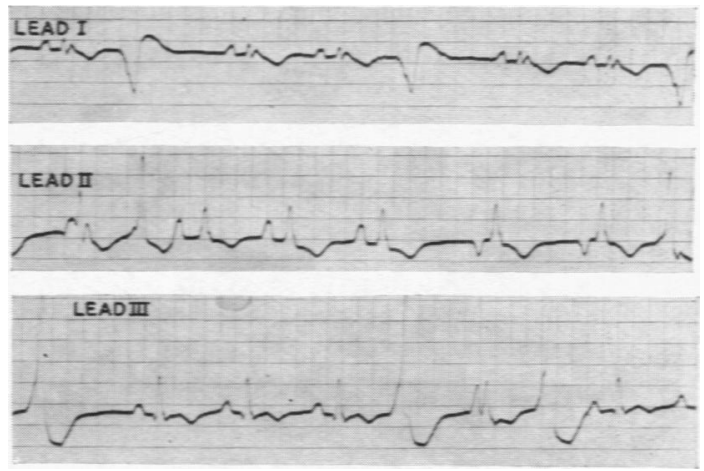

FK. 2-Taken after termination of initial paroxysm, showing $T$ wave inversion in all leads, prominent $P$ waves and multiple ectopic beats.

displaced 1 in. to the left of the midclavicular line. No murmurs could be heard. The blood pressure was $90 / 50 \mathrm{~mm} . \mathrm{Hg}$ and there was no evidence of congestive cardiac failure. All other systems were normal and she was afebrile. An electrocardiogram (Fig. 1) showed a rapid rate and an abnormal rhythm. There was considerable doubt and difference of opinion both at the time, and later, as to whether the tracing showed auricular or ventricular tachycardia, but subsequent events suggest that it was probably ventricular.

The effect of vagal stimulation was first tried with no success, and the child was then given 'digoxin', $0 \cdot 125 \mathrm{mg}$. orally, repeated in four hours. This had no effect and 'quinidine' was tried next and $100 \mathrm{mg}$. ( $1 \frac{1}{2}$ grains) was given two-hourly for three doses, without effect, and both drugs were then repeated in the same doses; again without effect. By this time, three days after admission, the heart was further enlarged to the left and the liver palpable $\frac{1}{2}$ in. below the costal margin, but there was no oedema, and the jugular venous pressure was not raised. It was decided to try intravenous procainamide, and in the next 20 hours three doses of $200 \mathrm{mg}$., $250 \mathrm{mg}$., 

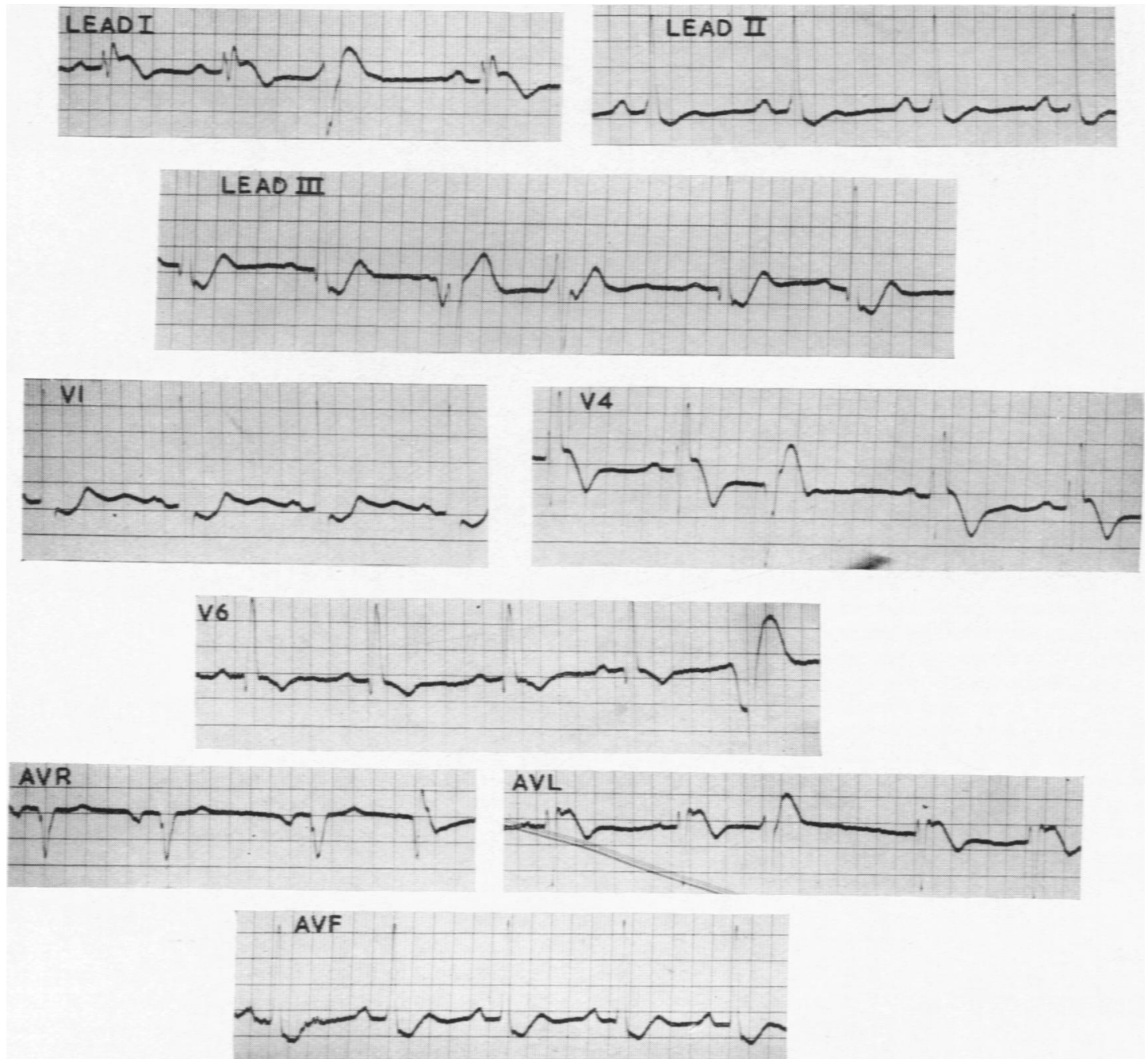

Fig. 3.-Showing displacement of the ST segment, with occasional ectopic beats.

and $200 \mathrm{mg}$. respectively were given slowly with continuous electrocardiographic and blood pressure recordings. The heart rate was slowed slightly to about 140 per minute but there was no change in the character of the tracings. The systolic blood pressure did not fall below 70 and rose again quickly after the injection.

Four days after admission she was given $0.25 \mathrm{mg}$. of 'digoxin' intravenously and within two hours her heart rate dropped to 90 per minute. An electrocardiograph (Fig. 2) showed sinus rhythm with multiple ectopic beats. The $P$ waves were large and the $T$ waves inverted in all leads. Digoxin was continued orally in doses of $0.125 \mathrm{mg}$. at first, four-hourly, and then at intervals of eight hours.

Forty-eight hours after the termination of the first attack she again developed tachycardia and an E.C.G. showed a reversal to the same abnormal rhythm. Again 'digoxin', 0.25 mg. intravenously, terminated the attac k.

During the next four weeks further paroxysms occurred and it was not found possible to discontinue the 'digoxin'. Increasing doses were necessary and she was finally controlled on $0.25 \mathrm{mg}$. twice daily. During this time repeated E.C.G. tracings were taken. The initial $T$ wave inversion in all leads disappeared in a few days and was attributed to functional changes in the myocardium secondary to the prolonged attack of tachycardia. The $P$ waves also became less prominent. Multiple multifocal ectopic complexes continued to be seen and progressive ST changes were noticed, especially in the anterolateral and left ventricle surface leads; this was taken to indicate extensive myocardial necrosis in this region (Fig. 3). On one occasion a tracing included a 
change-over from ectopic to sinus rhythm (Fig. 4) and showed very clearly the multifocal nature of the disturbance of the rhythm.
$4 \mathrm{~cm}$. The origins of the great vessels were all normal and the coronary arteries were normal in origin and distribution but followed a tortuous course. A radio-

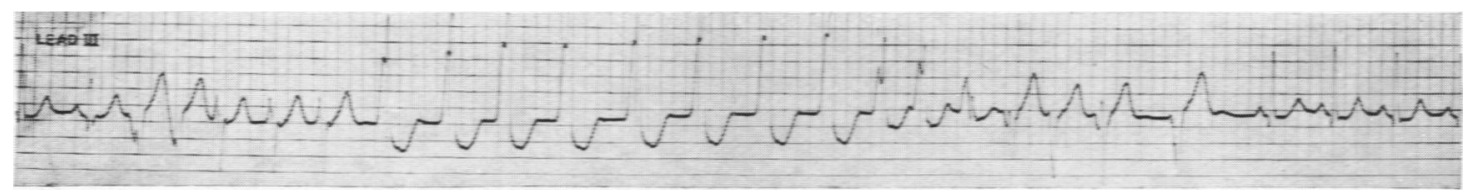

Fig. 4.- Lead III taken just after a further attack of paroxysmal tachycardia showing the change from abnormal to sinus rhythm, and the multifocal nature of the ectopic beats.

Radiographs showed a grossly enlarged left ventricle with a small area of calcification in its centre (Figs. 5 and 6). All other investigations, including blood films, sedimentation rates, blood chemistry and radiography of long bones, were normal.

An attempt was made to control the ectopic beats by adding 'quinidine', $200 \mathrm{mg}$. (3 grains), three times a day. This was, however, only partially successful, and after four months in hospital she was sent home on digitalis and 'quinidine', as it was felt that the prognosis was very grave. She remained at home for about three weeks only as she was vomiting and seemed ill and unhappy, and was therefore readmitted. No obvious change was noticed in her clinical condition but the E.C.G. showed further changes in the ST segment (Fig. 7). Four days after admission she died suddenly in her sleep.

Morbid ANATOMY. At necropsy nothing abnormal was found outside the heart; this was enlarged and grossly abnormal in appearance. The anterior aspect presented an irregular, whitish, nodular appearance (Fig. 8) and was the site of a tumour measuring $6 \mathrm{~cm}$. $\times 5 \mathrm{~cm}$. $\times$

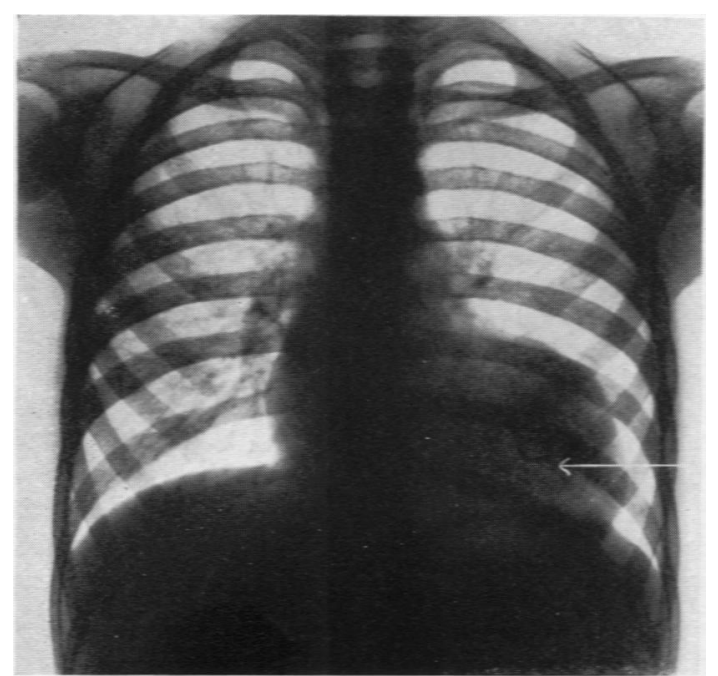

Fic. 5.-Enlargement of the left ventricle with an area of calcification. graph of the heart after removal and before section showed many specks of calcification; the largest was identified as the area of calcification visible in chest radiographs taken during life (Figs. 5 and 6 ).

On section the tumour presented the dense, white, whorled appearance seen in uterine fibromata (Fig. 9) and there was no definite capsule. A histological section shows a cellular fibroma which seems to be innocent although the myocardium appears to be almost strangled by the growth. Small islands of residual cardiac muscle can be seen scattered throughout the substance of the tumour (Fig. 10).

The diagnosis of a tumour was not made during life. The most favoured suggestion had been fibro-elastosis of the left ventricle, as it was felt that this would account for the left ventricular damage and possibly for the widespread disturbance of conducting tissue. Against this were the age and previous normal health of the child. Other possibilities considered were acquired coronary artery occlusion, and an anomalous origin of the left coronary artery from the pulmonary trunk; but neither was thought to fit the picture at all closely.

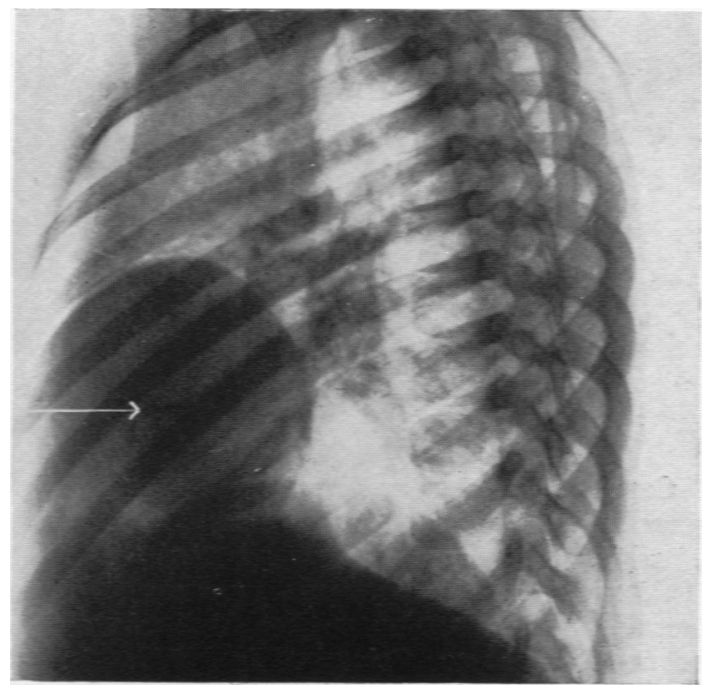

Fig. 6.-Oblique view showing the tumour 'end on'. Cakcification is visible as a horizontal line. 

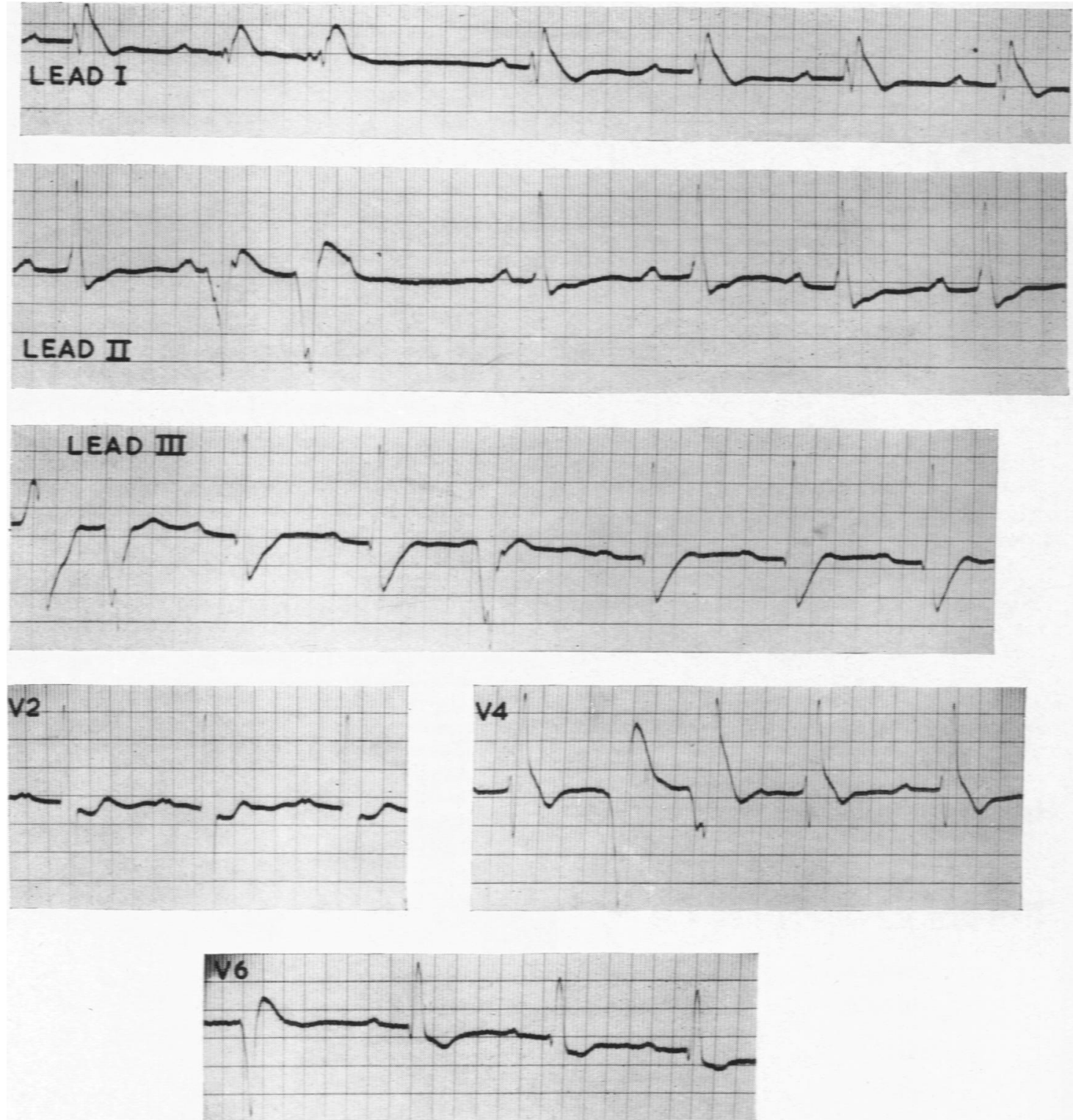

Fig. 7.-E.C.G. taken shortly before death showing further alteration in ST segment.

\section{Discussion}

Cardiac tumours are rare, and Yater (1931) recorded 150 primary cases from the literature of which about $20 \%$ were malignant. Mahaim (1945) collected 456 primary tumours from the literature, and attributes the first description of a fibroma to Colombo in 1559. In all Mahaim was able to collect 37 recorded cases of fibroma of which eight were polypoid and 29 non-polypoid, though many of these are without histological proof.

Considerable controversy has arisen over the aetiology of primary benign cardiac neoplasms, and some authors will not accept a fibroma as a true tumour. Prichard (1951) classes fibromata and hamartomata together, pointing out that in the heart a hamartoma may be composed of muscle, fibrous tissue, endothelium, blood vessels, fat, 


\section{FIBROMA OF LEFT VENTRICLE IN A CHILD}

nerves, or a combination of these elements. If this view is accepted then some myxomas, lipomas, and all of the rhabdomyomas and angiomas could be included in this category. However, most cases reported as hamartomas most closely resemble fibromas. Mahaim (1945) does not agree with this concept and classifies fibromata as polypoid, mural,

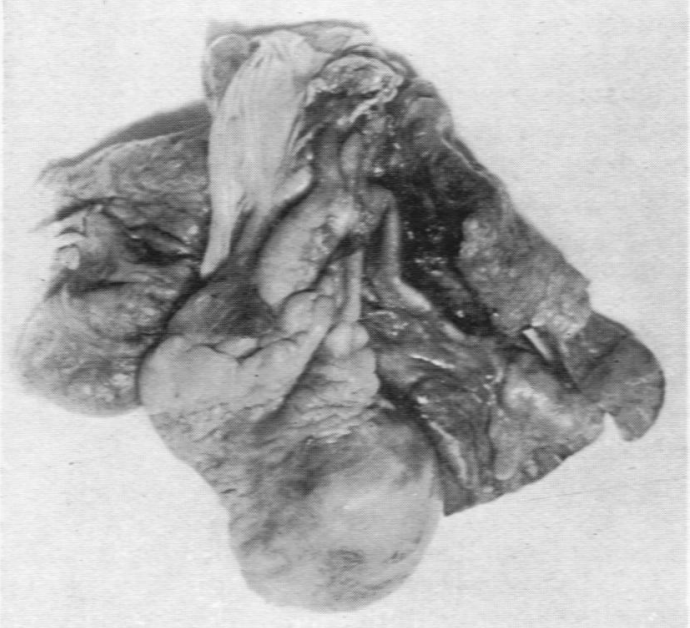

Fig. 8.-Anterior surface of the heart and lungs, showing the surface of the tumour.

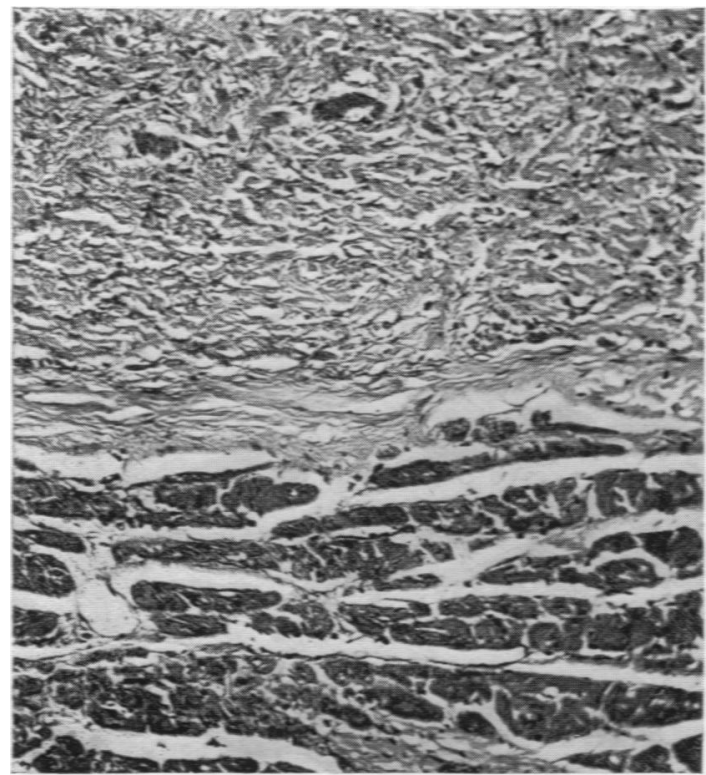

Fig. 10. - Section showing tumour and cardiac muscle. $\times 120$ and a third category of fibrous papillomata on the valves giving rise to valvular murmurs.

We have reported our case as a fibroma in view of the white whorled appearance of the tumour which had no definite capsule, and the typical histological picture. The presence of mucin and elastic tissue were excluded by specific staining methods.

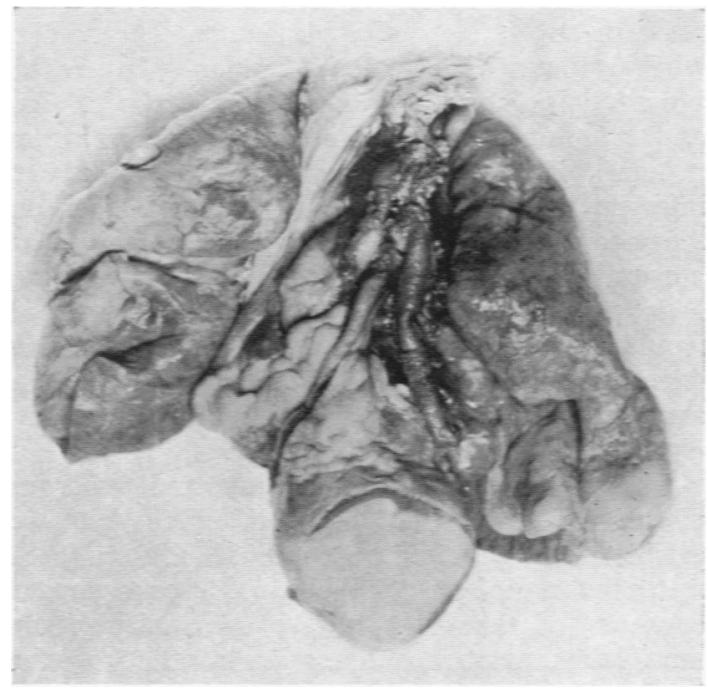

Fig. 9.-Anterior surface of the heart with a section of the tumour removed showing dense, white tumour tissue surrounded by a narrow edge of muscle.

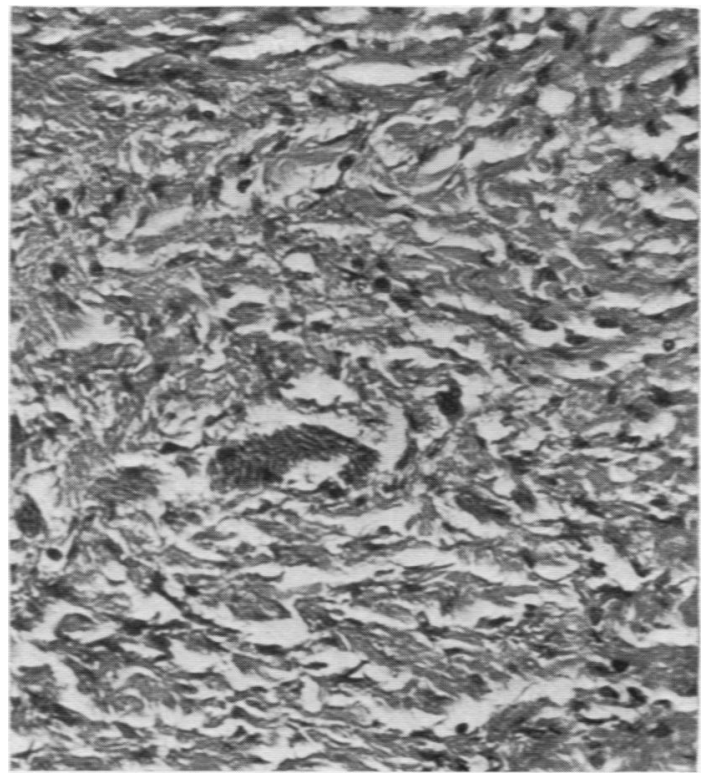

Fig. 11. - Section of tumour. $\times 260$ 
The recognition of cardiac tumours in life is difficult. Yater (1931) divides cases into two clinical groups. The first group present with terminal heart failure, sudden death or symptoms suggestive of bacterial endocarditis, and the second group suggest the presence of a cardiac tumour by virtue of heart block, cardiac dysfunction without apparent cause in a patient known to have a malignant process, haemorrhagic pericardial or pleural fluid, or suggestive radiological appearances. The clinical picture must depend upon whether the tumour is polypoid when it may give rise to signs and symptoms of valvular obstruction or incompetence. The mural tumours are more likely to interfere with the conducting system of the heart. Angiocardiography might be helpful in cases where a chamber of the heart is distorted, and in our case it is probable that the left ventricular chamber would have appeared small and misshapen. This, taken in conjunction with the radiological appearances of the apparent large left ventricle, could have given us valuable help.

Mahaim reports a case of intramural fibroma discussed by Macherey (1937) in which there was calcification visible on radiographs. Pfeiffer (1952) states that radiological findings of masses or unusual contours of the heart not easily explicable and unexplained or atypical alteration in rate or rhythm on the electrocardiogram with a tendency to rapid and sudden changes in the degree and type of aberration, or electrocardiographic changes suggestive of coronary occlusion, may lead to the recognition of a cardiac neoplasm. In our case an unusual contour of the heart was visible together with calcification; the electrocardiogram showed alteration of rate and rhythm and the later findings were suggestive of coronary occlusion. Unfortunately these findings did not lead us to a diagnosis during life.

Siegel and Young (1933) report a case of tumour affecting the left ventricle and septum in which the electrocardiogram at first suggested myocardial damage from coronary disease, despite the negative history of the patient. The $T$ waves were constantly inverted in all leads, and their direction was not reciprocal in leads I and III as is usual in recent coronary thrombosis, and also there were no day-to-day changes. Other authors (Lloyd, 1929; Willius and Amberg, 1930; Houck and Bennett, 1930) describe electrocardiograms associated with cardiac neoplasms, and in all the rhythm was normal, but there was no constancy of the isoelectric level in the ST segment.

Rosenbaum, Johnston, Alzamora and Mich (1944) reported a case of extensive secondary carcinoma involving the left ventricle and most of the right ventricle in which serial electrocardiograms showed persistent upward displacement of the RS-T segment in leads II, III and $V_{Y}$, and in a number of unipolar leads. They attribute these changes to the continuous acute myocardial injury as the neoplasm infiltrated the cardiac musculature.

Electrocardiograms are not available for many recorded cases of primary heart tumours since many have had no cardiac symptoms and the tumour has been found unexpectedly at necropsy.

\section{Summary}

A case of mural fibroma of the left ventricle in a child of $4 \frac{1}{2}$ years is described, and is discussed in relation to diagnosis during life. The literature on primary benign cardiac neoplasms is briefty reviewed, and the recognition and treatment of such tumours is discussed.

Our thanks are due to Dr. B. J. Haram who performed the necropsy, and to Dr. R. E. Bonham Carter and Dr. Paul Wood for helpful advice in the management of the case.

\section{References}

Houck, G. H. and Bennett, G. A. (1930). Amer. Heart J., 5, 787. Lloyd, P. C. (1929). Bull. Johis Hopk. Hosp., 44, 149. Macherey, w. (1937). (Reported by Mahaim.) Ziegl's. Beitr. pathol. Anat., Si, 565.

Mahaim, I. (1945). Les Twonewars et les Polypes du Coeve. Paris. Pfeifier, M. (1952). Postgrad. Med., 11, 438.

Prichard, R. W. (1951). Arch. Path., Chicago, 51, 98.

Rosenbaum, F. F., Johnston, F. D., Alamora, V. V. and Mich, A. A (1944). Amer. Heart J., 27, 667.

Siegel, M. L. and Youns, A. M. (1933). Ibid., 8, 682.

Willius, F. A. and Amberg, S. (1930). Med. Clin. N. Amer., 13, 1307. Yater, W. M. (1931). Arch. intern. Med., 48, 627. 